\title{
Effect of Chromium on the Mechanical Properties of Powder-Processed Fe-0.35 wt \% P Alloys
}

\author{
Shefali Trivedi *, Yashwant Mehta, K. Chandra, P.S. Mishra \\ Indian Institute of Technology, Roorkee- 247667, Uttarakhand, India \\ *Corresponding Author: shefalitrivedi2k8@gmail.com
}

\begin{abstract}
The role of chromium in high density $\mathrm{Fe}-\mathrm{P}$ binary, $\mathrm{Fe}-\mathrm{P}-\mathrm{Cr}$ ternary alloys is observed by characterization in terms of microstructure, porosity content/densification, hardness and tensile properties. The alloys were made using a hot powder forging technique. In this process mild steel encapsulated powders were hot forged into slabs, hot rolled and annealed to relieve the residual stresses. Densifications as high as $98.9 \%$ of theoretical density have been realized. Microstructures of these alloys consist of single-phase ferrite only. $\mathrm{Fe}-0.35 \mathrm{P}, \mathrm{Fe}-0.35 \mathrm{P}-2 \mathrm{Cr}$ alloys showed very high ductility. As forged and hot rolled Fe-0.35P alloy showed very high elongation and it improved further on annealing. It was observed in this present investigation that, the alloying addition, such as $\mathrm{Cr}$ to $\mathrm{Fe}-\mathrm{P}$ based alloys caused increase in strength associated with the reduction in ductility. Alloys developed in the present investigation were capable of hot/cold working to very thin gage of sheets and wires.
\end{abstract}

Key words: Phosphoric Iron, Mechanical properties, Powder Metallurgy, Forged, Ancient iron.

\section{INTRODUCTION}

The role of chromium in temper embrittlement has been explained on the basis of the cosegregation model proposed by Guttmann [1]. According to this model both chromium and phosphorus in wrought route have a tendency to segregate to grain boundaries, and an attractive energetic interaction occurs between them. Thus they attract each other at grain boundaries and increase the segregation of the partner. In contrast, it has been reported that chromium has no effect on the segregation of phosphorus in iron based alloys [2] and low alloy steel in which the bulk concentration of chromium is varied [3]. The intrinsic effect of chromium has been considered to be an increase in the embrittling potency of phosphorus and a reduction in the grain boundary cohesion [3-5]. In contrast to the above, Kimura has shown that the addition of chromium to a high purity Fe- $0.25 \% \mathrm{P}$ alloy decreased the ductile-brittle transition temperature (DBTT) [6]. 
Phosphorous helps carrying alloy constituents into iron matrix which are otherwise sluggish to diffuse. P significantly improves ductility and strength of Fe-P based alloys [7]. Cr improves formability of Fe-P based alloys [8]. It is therefore, realized that, the Fe-P based alloys, containing alloying elements, such as $\mathrm{Cr}$ could be used for structural application because of their higher strength than pure iron with reasonably good ductility. Since all these alloying elements are ferrite stabilizers, ferrite phase will be stable even at high temperature when substantial alloying is completed. Self-diffusion coefficient of iron [9] and inter-diffusion coefficient of the alloying elements in ferrite is much higher than that in austenite. This diffusion helps in reducing amount of pores in the $\mathrm{P} / \mathrm{M}$ part. However, during alloying process some additional pores may be created [9] (due to dissolution of elemental particles). However, if we follow the traditional powder metallurgical process, such as compaction and sintering, for manufacturing high phosphorous Fe-P based alloys, heavy volume shrinkage will be experienced [10].

There are several other densification processes available in the literature. Out of all densification processes available, hot iso-static pressing (HIP) is the best as far as density and performance of these $\mathrm{P} / \mathrm{M}$ parts are concerned. However, the process is extremely costly. Therefore, some pseudo HIP processing could be used for manufacturing these alloys to reduce the cost of processing without sacrificing the benefit of HIP processing. However, HIP process does not have scope of cleaning particle surfaces during processing. Furthermore, existence of prior particle boundaries (PPB) renders them unsuitable because PPB's are source of impurity concentration resulting in inter-particle brittle failure. In view of this, in the present investigation, the densification of the Fe-P based alloys were carried out by hot powder forging [8] technique. Volume shrinkage associated with these alloys is also no more a consideration in hot powder forging. Hot powder forging has another feature which is not available with compacting in a die or HIP. It is essentially the process where shaping and consolidation are deformation based. This causes redistribution of residual impurities (deformation can move them around but diffusion moves them into the matrix) situated at the particle surfaces and results in improvement in the properties of the final product [11].

\section{EXPERIMENTAL}

For making iron-phosphorous, iron-phosphorous-chromium alloys by powder metallurgical technique, iron powder (Fe-99.99 wt\%, C-0.00 wt\%) (-100 mesh) was mixed with ironphosphide (C- $0.00 \mathrm{wt} \%)(-100 \mathrm{mesh})$ with/without addition of low carbon ferro-chromium $(\mathrm{C}<$ $0.01 \mathrm{wt} \%)(-200 \mathrm{mesh})$. Whereas, iron and low carbon ferro-chromium powders were of commercial purity, iron-phosphide powder was prepared by mixing iron powders with orthophosphoric acid and subsequent reducing heat treatment $\left(800{ }^{\circ} \mathrm{C} / 2 \mathrm{~h} / \mathrm{H} 2\right)$. The reactions are as follows:

$$
\begin{aligned}
& \mathrm{Fe}+\mathrm{H}_{3} \mathrm{PO}_{4}=\mathrm{Fe}_{3}\left(\mathrm{PO}_{4}\right)_{2} \ldots \ldots \ldots \\
& \mathrm{Fe}_{3}\left(\mathrm{PO}_{4}\right)_{2}+8 \mathrm{H}_{2}=\mathrm{Fe}_{3} \mathrm{P}+8 \mathrm{H}_{2} \mathrm{O}
\end{aligned}
$$

The powder blends were manually mixed to make different alloys. About $500 \mathrm{~g}$ of each blended mixture was then poured in a mild steel capsule (as shown in Fig. 1). The encapsulated powders 
were heated in a tubular furnace at $1150{ }^{\circ} \mathrm{C}$ for $45 \mathrm{~min}$ in dry hydrogen atmosphere in order to remove the oxide layer from the surfaces of the powders. Heated capsules were then forged with a 200T capacity friction screw press to make slabs using a flat/channel die. Two powder metallurgical alloys were made in the present investigation. These are:

(1) $\mathrm{Fe}-0.35 \mathrm{wt} \% \mathrm{P}$ alloy

(2) $\mathrm{Fe}-0.35 \mathrm{wt} \% \mathrm{P}-2 \mathrm{wt} \% \mathrm{Cr}$ alloy.

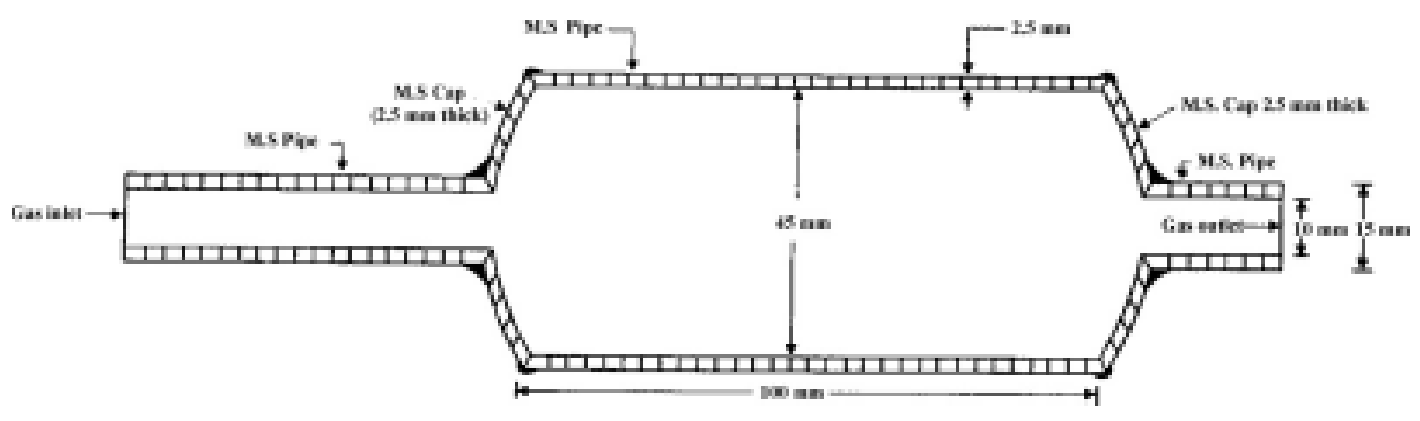

Fil. 1. Cooss-section of mild steel capule wed in the present imestigation.

The compositions of these alloys are based on the powder mixture. Alloys were made using channel die where side wall restriction to metal flow was imposed. Fig. 2 schematically illustrates the process of making slabs in hot powder forging technique. The slabs were then homogenized at $1200 \circ \mathrm{C}$ for $2 \mathrm{~h}$ depending on the alloy composition to eliminate compositional in homogeneity. All the alloying elements are present in the form of fine particles around pure iron particles. This iron particle is $100 \%$ gamma-phase at the homogenizing temperature. Phosphorous (in the form of ferro-phosphorous) combines with this gamma iron powder particle and dissolves in it. As it dissolves, it gets converted into ferrite (Fig. 3, 4) and as ferrite phase grows out of gamma phase, more and more phosphorous penetrates in it. This helps carry chromium in ferrite phase.

The mild steel encapsulation was then removed by machining. The slabs, after removal of mild steel skin, were hot rolled using flat roll and section roll at $900 \circ \mathrm{C}$ to make thin sheets and wires, respectively. Rolling was carried out very slowly at $900 \circ \mathrm{C}$ with $0.1 \mathrm{~mm}$ thickness/diameter reduction per pass. The rolling was done using small laboratory scale rolling mill with $10 \mathrm{~cm}$ roll diameter. The sheets and wires were then vacuum annealed at $950{ }^{\circ} \mathrm{C}$ for $40 \mathrm{~min}$ to relieve the residual stresses. All the samples prepared this way were characterized in terms of density, microstructure, hardness, and tensile properties as detailed below. Homogenized slabs as well as hot rolled and annealed sheets and wires were subjected to metallographic examinations. This includes volume percentage of porosity and grain size measurements.

The microstructures were taken at the cross-section of the as forged and homogenized slabs as well as rolled and annealed sheets and wires. Cross-section for sheet in this case is along short transverse direction. Calculated volume percentage porosities matched with the metallographically measured volume percentage porosities. Hardness of the hot rolled and 
annealed wires were measured with Vicker's hardness tester using $10 \mathrm{~kg}$ load. For tensile testing, samples were either punched out of sheet, or wires were directly tested using Hounsfield tensile tester. The tensile testing were carried out at room temperature with a cross head speed 1 $\mathrm{mm} / \mathrm{min}$. Gauge length of the specimens was $20 \mathrm{~mm}$. Gauge diameter of the tensile sample (wires) was $1 \mathrm{~mm}$.

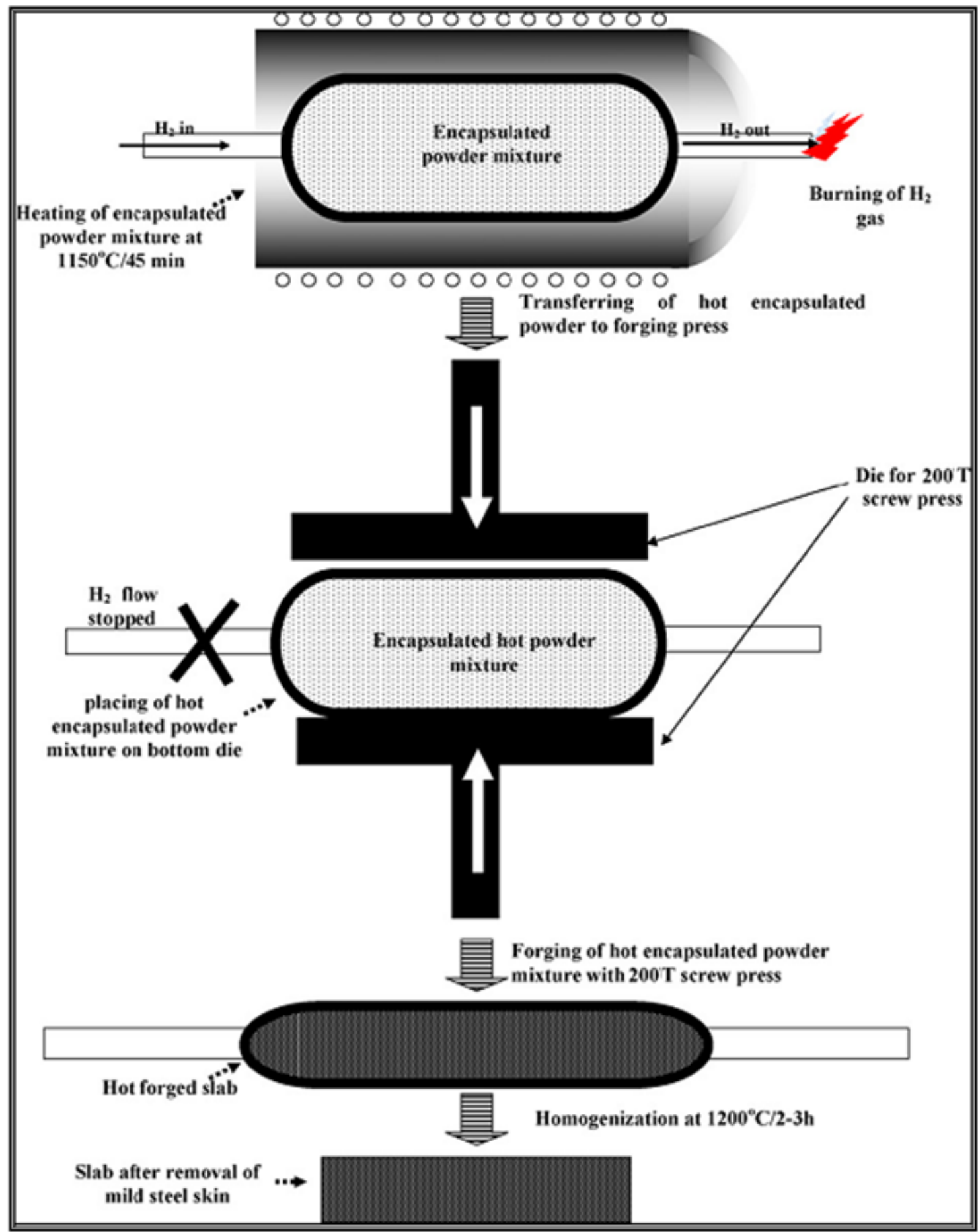

Fig.2: Schematic diagram illustrating the production of slab by hot forging of encapsulated powder mixture. 


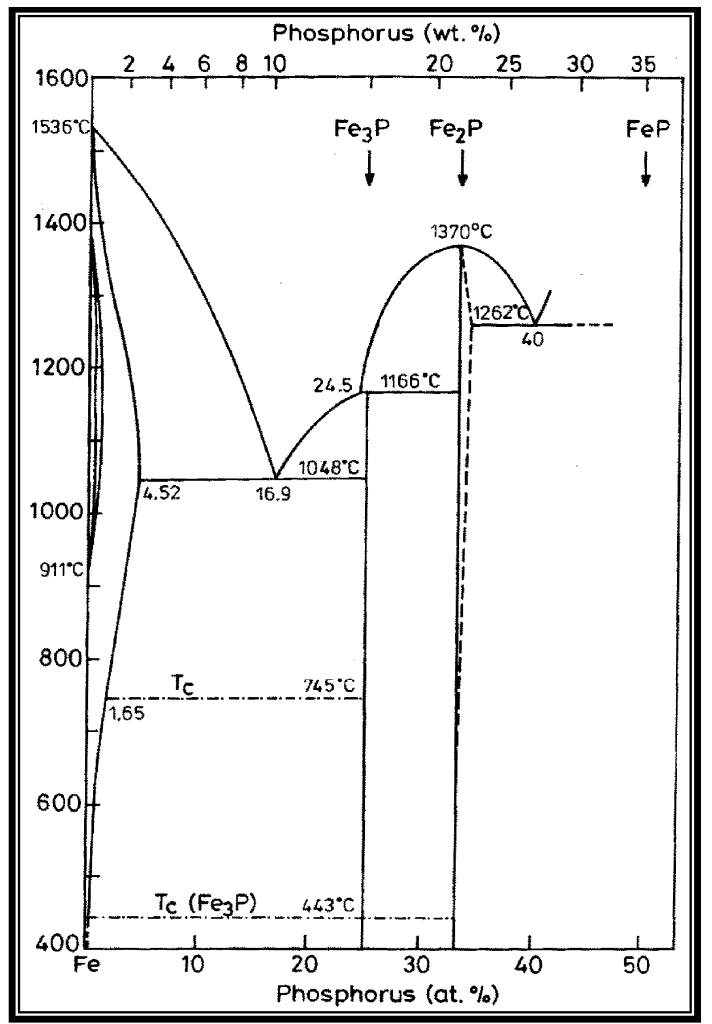

Figure 3. Fe-P binary phase diagram (Kubaschewski 1982).

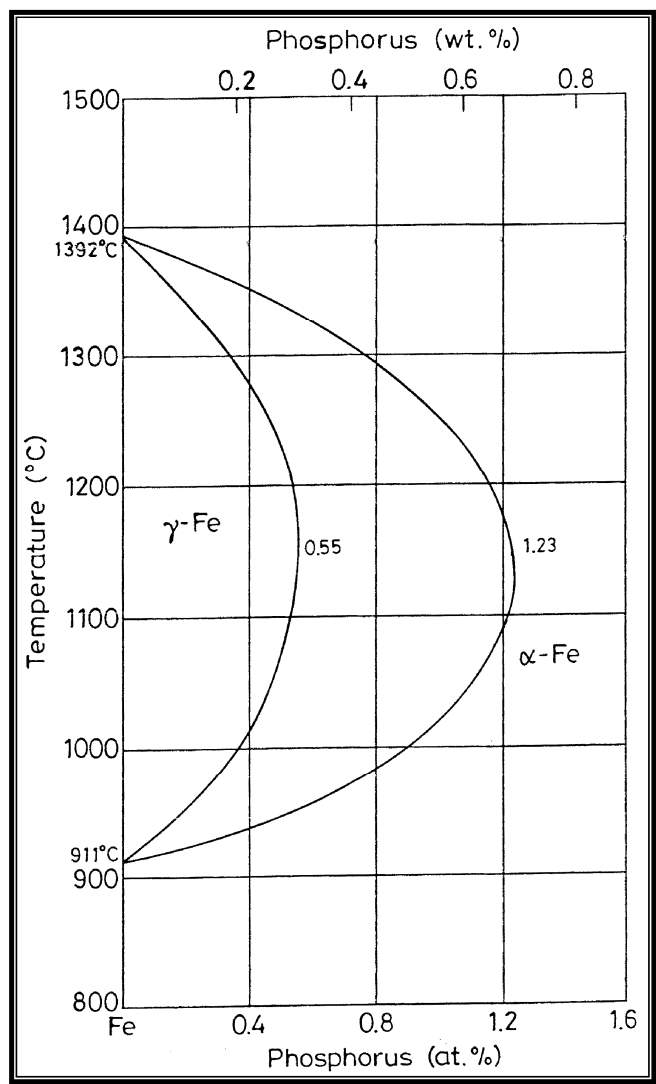

Fig. 4. High temperature gamma loop region of the Fe-P phase diagram (Kubaschewski 1982). 


\section{RESULTS AND DISCUSSIONS}

Table 1 shows the chemical composition of the two alloys in weight percentage. Volume percentage porosities were estimated from the measured density of the specimens. These estimated volume percentage of porosities are recorded in Table 2. In order to verify the correctness of the estimated volume percentage of porosity, the porosities were also measured using quantitative metallographic. As forged and homogenized microstructures as well as rolled and annealed microstructures with the experimentally measured volume percentage of porosity were recorded and shown in Fig. 5. They are more or less matching with the theoretically calculated volume percentage porosity. These observations are in agreement with the theoretically calculated volume percentage porosity which also showed the similar trend. It was found that volume percentage of porosity in grain interior is higher than grain boundaries. The wires are made using section rolls. The cross-sections of the thin wires are shown in Fig. 6. The cross-sections of the rolled wire showed the porosities which were elongated toward the rolling direction, these are almost rounded porosity. To reveal grain boundaries sample were etched and are shown in Fig. 6.

Table 1: Chemical composition of Phosphoric alloys (Weight percentage)

\begin{tabular}{|c|c|c|c|}
\hline Sample & P & Cr & Fe \\
\hline (a) & 0.35 & - & Balance \\
\hline (b) & 0.35 & 2 & Balance \\
\hline
\end{tabular}

Table 2: Calculated volume percentage of porosities of the alloys

\begin{tabular}{|c|c|c|c|c|c|}
\hline Sample N & $\begin{array}{l}\text { As } \\
\text { forged } \\
\text { density } \\
(\mathrm{g} / \mathrm{cc})\end{array}$ & $\begin{array}{l}\text { Rolled a } \\
\text { annealed } \\
\text { density } \\
(\mathrm{g} / \mathrm{cc})\end{array}$ & $\begin{array}{l}\text { Theoretical } \\
\text { density } \\
(\mathrm{g} / \mathrm{cc})\end{array}$ & $\begin{array}{lr}\text { Porosity in } & \text { Rolled } \\
\text { annealed } & \text { wir } \\
\text { calculated } & \text { usi } \\
\text { measured } & \text { dens } \\
(\mathrm{vol} \%) & \end{array}$ & $\begin{array}{l}\text { Porosity in Rolled \& } \\
\text { annealed wires, calculate } \\
\text { using quantitative } \\
\text { metallographic technique } \\
\text { (vol \%) }\end{array}$ \\
\hline (a) & 7.272 & 7.693 & 7.844 & 1.9 & 3.12 \\
\hline (b) & 7.272 & 7.586 & 7.77 & 2.36 & 3.44 \\
\hline
\end{tabular}
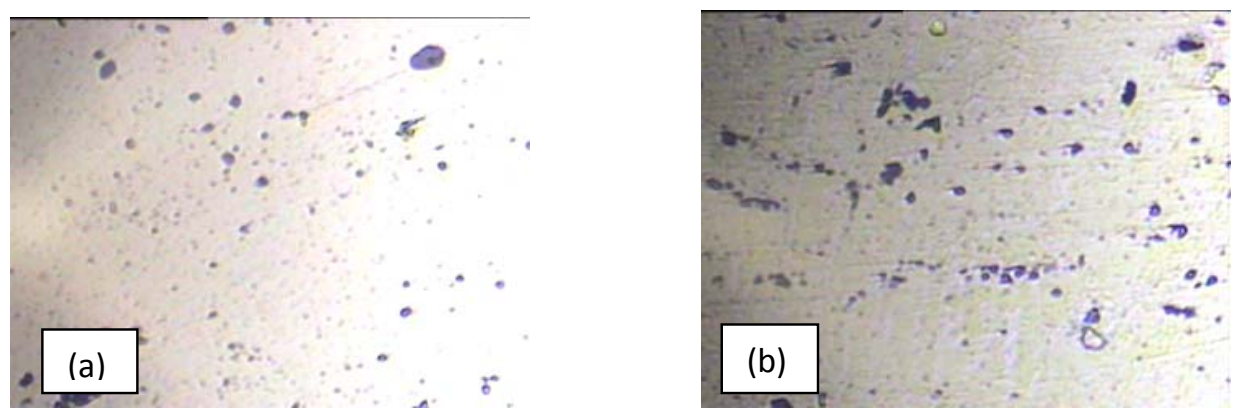

Fig. 5. Porosity distribution of the rolled and annealed wires in as polished and unetched condition (magnification 200X). 

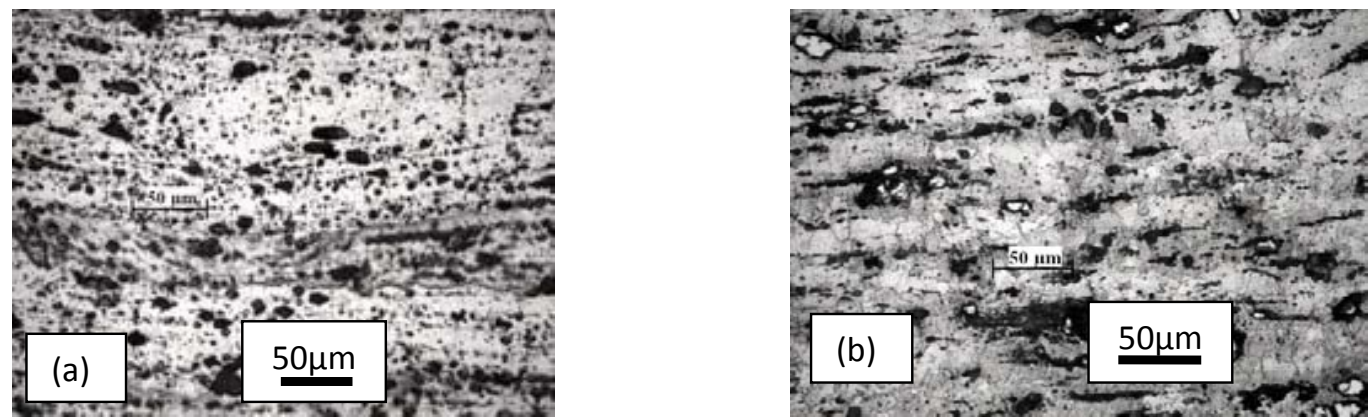

Fig. 6. Cross-section of hot rolled and annealed alloys (etched with $2 \%$ nital) revealing grain structure. Residual alignment of porosity and flattening of pores are observed in all these rolled and annealed alloys.

Powder metallurgical phosphoric irons developed in the present investigation are free of any segregation of the alloying elements along the grain boundaries. They get distributed uniformly in the entire structure. This has been confirmed by: Optical Microscope (Fig. 6), Surface Morphology (SEM) and EDAX Pattern from different Spots (Fig. 7, 8), Composition Image [Secondary Image] \& Line scanning (Fig. 9). The hardness was found to increase with both, P \& Cr. Fig. 10 shows the hardness of different $\mathrm{P} / \mathrm{M}$ alloys made in this investigation. Combined effect of chromium and phosphorous causes more hardening of ferrite than that obtained due to silicon in solid solution with iron [11]. However, porosity also affected the hardness of these products. The alloy $\mathrm{Fe}-0.35 \mathrm{P}-2 \mathrm{Cr}$ with only 3.44 vol\% porosity showed the hardness of 190 $\mathrm{Hv} / 10 \mathrm{~kg}$. The alloy Fe- $0.35 \mathrm{P}$ with a porosity of $3.14 \mathrm{vol} \%$ showed hardness of $183.4 \mathrm{Hv} / 10 \mathrm{~kg}$. Had there been similar porosity level of these two alloys, improvement in hardness due to $\mathrm{P}$ and $\mathrm{Cr}$ alloying addition could have been realized. However, hardness improvements due to $\mathrm{P}$ and $\mathrm{Cr}$ addition were realized truly in the case of two alloys. Fe-P based alloys containing $0.35 \mathrm{wt} \% \mathrm{P}$ showed moderate ductility. Tensile properties, such as yield strength, tensile strength, elongation of these alloys are shown in Table 3.
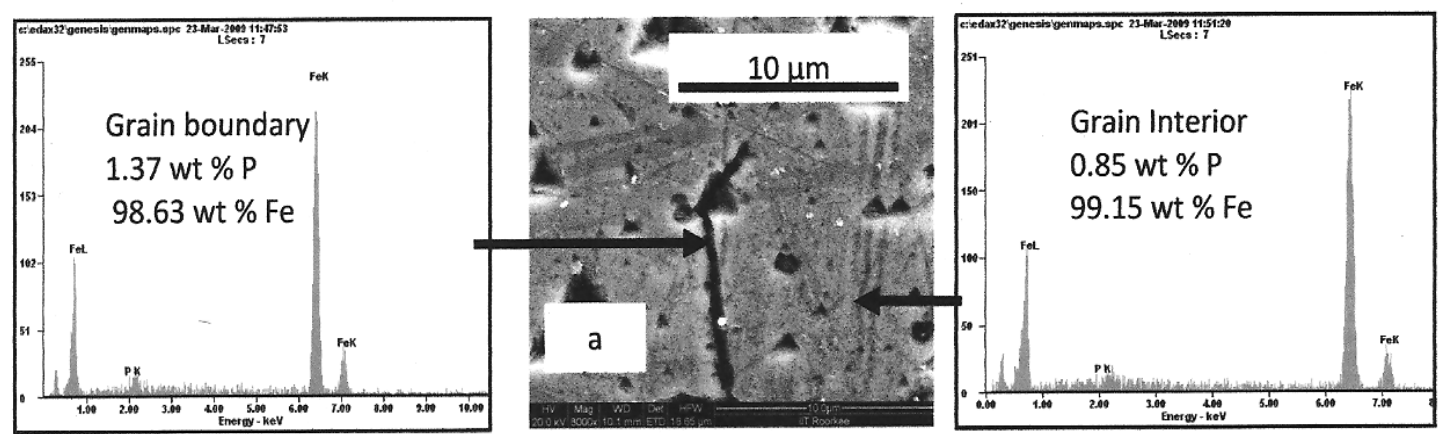

Fig. 7. Surface Morphology (SEM) and EDAX Pattern from different Spots of sample (a). 


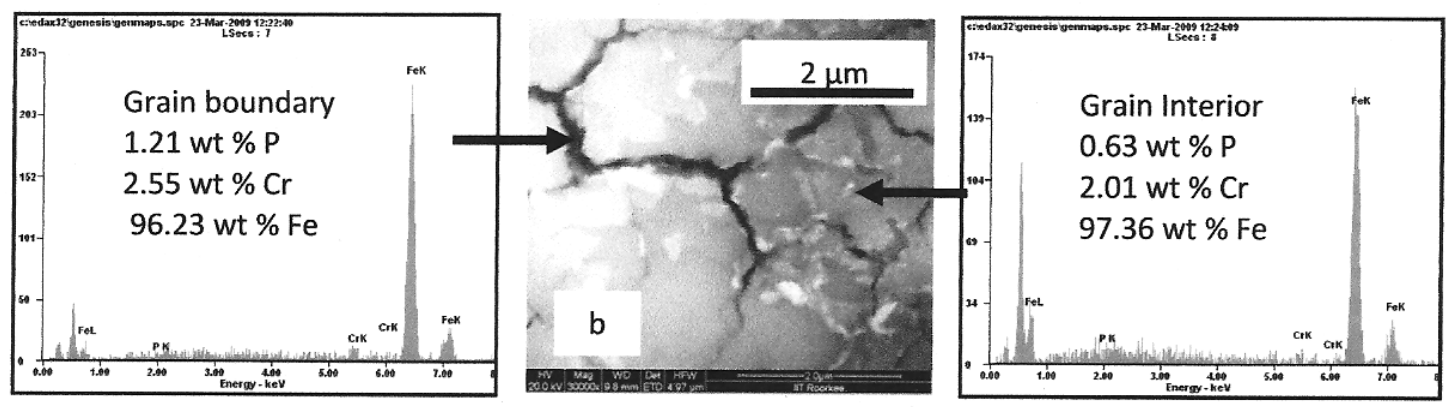

Fig. 8. Surface Morphology (SEM) and EDAX Pattern from different Spots of sample (b).
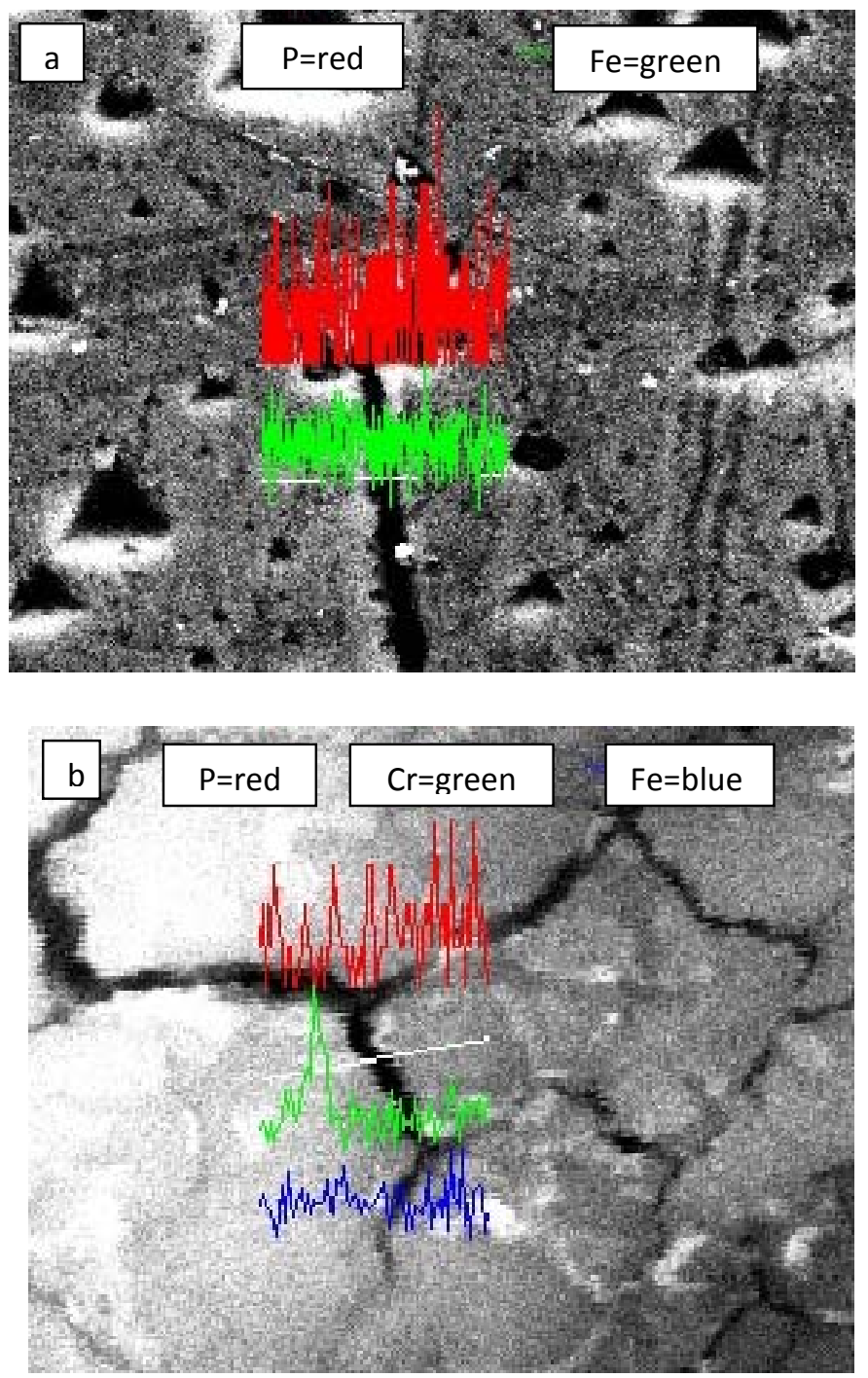

Fig. 9. Composition Image [Secondary Image] \& Line scanning of sample (a) and sample (b). 


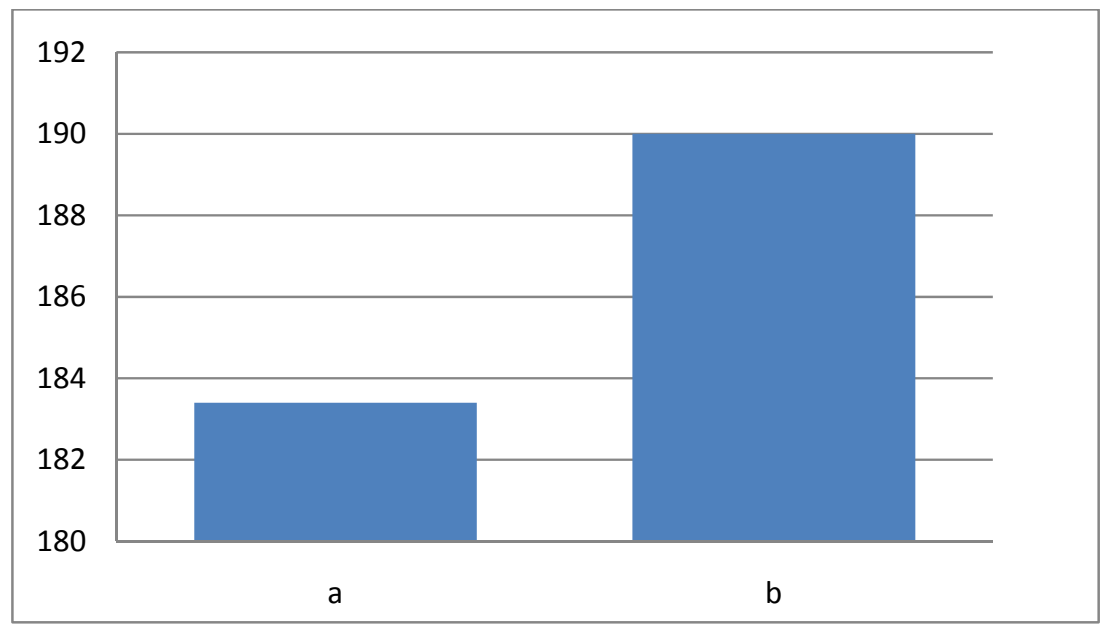

Figure 10: Graphical Representation of the variation in Hardness of Alloys

Table 3: Mechanical Properties of Fe-P alloys

\begin{tabular}{|c|c|c|c|}
\hline Sample & Proof Stress(MPa) & UTS(MPa) & Total Elongation (\%) \\
\hline (a) & 178 & 276 & 6.0 \\
\hline (b) & 278.9 & 356 & 4.23 \\
\hline
\end{tabular}

\section{CONCLUSIONS}

The following conclusion can be drawn from the present investigation:

i) Alloys developed in the present investigation have very good hot/cold workability.

ii) Alloys containing $\mathrm{Cr}$ showed higher strength $(>350 \mathrm{MPa})$ and higher resilience value with moderate ductility under annealed conditions with scope for developing higher strengths by cold working.

iii) As forged and homogenized as well as rolled and annealed $\mathrm{Fe}-\mathrm{P}$ based alloys developed in the present investigation were characterized using metallographic technique. All the microstructures show single-phase ferrite grains with porosities well distributed along the grain boundaries as well as inside the grains.

iv) Chromium improved the strength without much reduction in ductility of sample (b) as compared to sample (a)

v) Improvement in hardness levels due to the combined addition of Chromium was found.

\section{REFERENCES}

[1] Guttmann M., Surf. Sci., 1975, "Equilibrium segregation in a ternary solution: A model for temper embrittlement" vol 53 pp. 213-227.

[2] Erhart H. and Grabke H. J. 1981 "Equilibrium Segregation Of Phosphorus At Grain Boundaries Of Fe-P, Fe-C-P, Fe-Cr-P, And Fe-Cr-C-P Alloys", Met. Sci. Vol 15 pp 401 -408

[3] Briant C. L., Scr. Metall. 1981" The effect of nickel, chromium, and manganese on phosphorus segregation in low alloy steels" vol 15 pp 1013-1018 
[4] Briant C.L.and Messmer R.P., 1982,'The role of chemical bonding in grain boundary embrittlement Acta Metall.," vol 30 pp 457-467

[5] Lee D.Y., Barrera E. V., Stark J.P and Marcus H.L., 1984 "The Influence of Alloying Elements on Impurity Induced Grain Boundary Embrittlement," Metall. Trans, A, vol 15 pp $1415-1430$.

[6] Kimura H., 1988, "Intergranular Fracture in BCC Metals " Trans.Jpn.inst. Met., vol 29 pp 521-539

[7] Koczac M.J., Aggarwal P., 1978-1979 "The effect of particle size and density on the properties of iron and iron-phosphorous alloys", National Powder Metallurgy Conference Proceedings, Prog. Powder Metall. 34 and 35 pp 113-132.

[8] Chandra K, "Development of iron-P based soft magnetic materials by P/M route",Ph.D. Thesis, Department of Metallurgical and Materials Engineering, IIT Roorkee, India, May 2002. [9] Qu X., Gowri S., Lund J.A., January 1991 "Sintering behaviour and strength of Fe-Si-P compacts", Int. J. Powder Metall. Vol 27 (1) pp 9-13.

[10] Moyer K.H., 1998, Magnetic materials and properties for part applications ,ASM Hand Book on Powder Metallurgy \& Application vol. 7 pp 1006-1019.

[11] Das J., Chandra K., Mishra P. S., Sharma, B. , 2008 "Hardness and tensile properties of Fe-P based alloys made through powder forging technique", Materials Science and Engineering A 479 pp 164-170

[12] Kubaschewski O 1982 Iron-Binary phase diagrams (Berlin: Springer Verlag) pp 84-86 